Gazi University
Journal of Science
PART A: ENGINEERING AND INNOVATION
http://dergipark.org.tr/gujsa

\title{
Thermal and Computational Fluid Dynamics (CFD) Analysis of a Modified Two Stroke Spark Ignition Engine Block
}

\author{
Sunday BAKO ${ }^{1 *(\mathbb{D})}$ Jacob Nonom DOGO $^{1}$ (D) , Muhammed Bello UMAR ${ }^{1}$ (D) Ige BORI $^{2}$ (iD) \\ ${ }^{I}$ Department of Mechanical, Engineering, Nuhu Bamalli Polytechnic, Zaria, NIGERIA \\ ${ }^{2}$ Department of Mechanical, Engineering, Federal University of Technology, Minna, NIGERIA
}

\begin{tabular}{|c|c|}
\hline Keywords & Abstract \\
\hline $\begin{array}{l}\text { Conceptulization } \\
\text { Solidworks Simulation } \\
\text { Steady State Analysis } \\
\text { Transient State Analysis } \\
\text { CFD Analysis }\end{array}$ & $\begin{array}{l}\text { An engine block is the main supporting structure for other components of the engine. Poor heat } \\
\text { dissipation of the engine block causes excessive thermal expansion and frictional wearing of the } \\
\text { engine components and makes engine oil to lose its lubricating power. Therefore, there is a need to } \\
\text { modify the design of the engine block in order to improve its effectiveness. In this analysis, a two } \\
\text { stroke spark ignition engine block was initially used as a reference model for the development of the } \\
\text { modified model. Solidworks (2013) simulation software was used to model and conduct a thermal and } \\
\text { computational fluid dynamics (CFD) analysis on the two models. The thermal analysis results shows } \\
\text { that, the maximum temperature gradient and heat flux obtained during the steady state and transient } \\
\text { thermal analysis were, } 2.237 \times 10^{7} \mathrm{~K} / \mathrm{m}, 3.6817 \times 10^{4} \mathrm{~K} / \mathrm{m} \text {, and } 1.066 \times 10^{7} \mathrm{~W} / \mathrm{m}^{2}, 1.661 \times \\
10^{6} \mathrm{~W} / \mathrm{m}^{2} \text { for the reference model, while } 1.771 \times 10^{6} \mathrm{~K} / \mathrm{m}, 4.913 \times 10^{4} \mathrm{~K} / \mathrm{m} \text {, and } 7.970 \times 10^{7} \mathrm{~W} / \\
\mathrm{m}^{2}, 2.211 \times 10^{6} \mathrm{~W} / \mathrm{m}^{2} \text { for the modified model respectively. The results shows that the modified } \\
\text { model has an improved heat dissipation rate than the reference model. The CFD analysis shows that, } \\
\text { the reference model is subjected to high pressure and air resistance than the modified model. This } \\
\text { increases the drag force acting on the reference model. While the modified model has high air flow } \\
\text { velocity round the engine block, than the reference model. This is due to fins modification of the } \\
\text { modified model. This makes the engine block model to have low air restriction. It is hereby } \\
\text { recommended that further validation should be carried out to ascertain the effectiveness of the } \\
\text { modified model. The performance of the modified model can also be improved by converting its fins } \\
\text { into triangular fins geometry. }\end{array}$ \\
\hline
\end{tabular}

\begin{tabular}{lrl}
\hline Cite & \\
\hline \multicolumn{2}{l}{ Bako, S., Dogo, J. N., Umar, M. B., \& Bori, I. (2021). Thermal and Computational Fluid Dynamics Analysis of a Modified Two } \\
Stroke Spark Ignition Engine Block. GU J Sci, 8(4), 482-493. & \\
\hline Author ID (ORCID Number) & Article Process \\
\hline S. Bako, 0000-0003-2348-1217 & Submission Date & 12.10 .2021 \\
J. N. Dogo, 0000-0001-5791-870X & Revision Date & 07.12 .2021 \\
M. B. Umar, 0000-0001-6679-1835 & Accepted Date & 28.12 .2021 \\
I. Bori, 0000-0001-7001-094X & Published Date & 29.12 .2021 \\
\hline
\end{tabular}

\section{INTRODUCTION}

Unlike the earlier work done by Bako et al. (2021), on development and structural analysis of a modified two stroke spark ignition engine; this paper presents the thermal and computation fluid dynamics analysis of the modified two stroke spark ignition engine block. The paper tends to ascertain the thermal and the fluid dynamic behavior of the engine blocks. The engine block is the solid foundation for housing and supporting of other components of the engine. It is subjected to high structural and thermal stress during the compression and the expansion stroke of the engine. Approximately $30 \%$ of the heat energy released in the engine is converted into mechanical energy, while the remaining energy is lost in the form of heat and friction (Ansari et al., 2020). Therefore the cooling of the engine block needs to be improve because this high temperature can cause damage to engine components and lubricants. This heat is conducted to engine components, thereby causing high frictional wear and looses. Due to this effect, the engine efficiency is reduced (Subramanian et al., 2019). Uncontrolled heating of the engine causes expansion of the piston and piston rings, which will also increase frictional losses. The viscosity of the lubricating oil used in the engine, 
and the cooling system requirements are greatly affected by the engine heat dissipation rate. The two stroke engine blocks wear much faster than four stroke engines block (Jiang, 2015). Unlike the Gas Turbine (GT) engine that uses Brayton's Cycle, and the Steam Turbine (ST) engine that uses Rankine's Cycle (Bakare et al., 2016); the two stroke engine uses Otto's Cycle and it produces power during every crankshaft rotation. The heat released inside the engine increases frictional wear and affects the engine cycle efficiency (Thomas, 2009). Therefore, there is a need to come up with measures to improve the heat dissipation rate of the engine in order to improve its efficiency. This leads to the concept of the research.

Due to high demand for two stroke spark ignition engine in the global market and the need to improve the engine performance; some researchers (Thomas, 2009; Khan \& Shaikh, 2016; Schneider et al., 2016; Subramanian et al., 2019; Ansari et al., 2020) have carried out research works to analyze and to improve the engine efficiency. These engines are air cooled engines. The temperature of the engines is convectively cooled with the help of the cooling fins. In order to enhance the engine cooling, Jain et al. (2016) optimized the cooling system dimension of a two stroke air cooled internal combustion engine by reducing the total volume occupied by the engine. It was noted that, modifying cooling system and the entire engine design would reduce emission and improve engine efficiency. Babu \& Lavakumar (2013) and Rao \& Vardhan, (2013) analyzed the thermal properties of the engine by altering the fins geometry, material and thickness on the engine cylinder. While Yeh et al. (1997) and Dempsey (2010) recommended the addition and modification of fins on an engine cylinder, in order to increase its surface area for heat dissipation. Therefore, design modification of the engine cylinder is highly needed, in order to make the pressure and temperature distribution to be uniformly distributed on the engine block. This will reduce the waste of unburnt charges and decrease environmental pollution (Babu et al., 2013).

Most researchers primarily focused on design modification of the two stroke engine for alternative fuel usage and power density, as well as to achieve higher efficiency through more complex porting systems (Borman \& Nishiwaki, 1987; Blarigan \& Keller, 1998; Bernard \& Baranescu, 1999). Therefore the concept of this paper came up as a measure to improve the engine performance through fins modification. The first series of this research work presents the modeling and structural analysis of a modified two stroke spark ignition engine block. The work shows that, the modified model is more rigid and has more strength than the reference model. Therefore this paper as continuation, presents the thermal and computational fluid dynamics analysis of the modified two stroke spark ignition engine block. The paper aimed at conducting and comparing the thermal and aerodynamics performance of the two respective models, and to ascertain the model with improved heat dissipation, and aerodynamics behaviors. Figure 1 illustrates the working principle of the two stroke spark ignition engine.
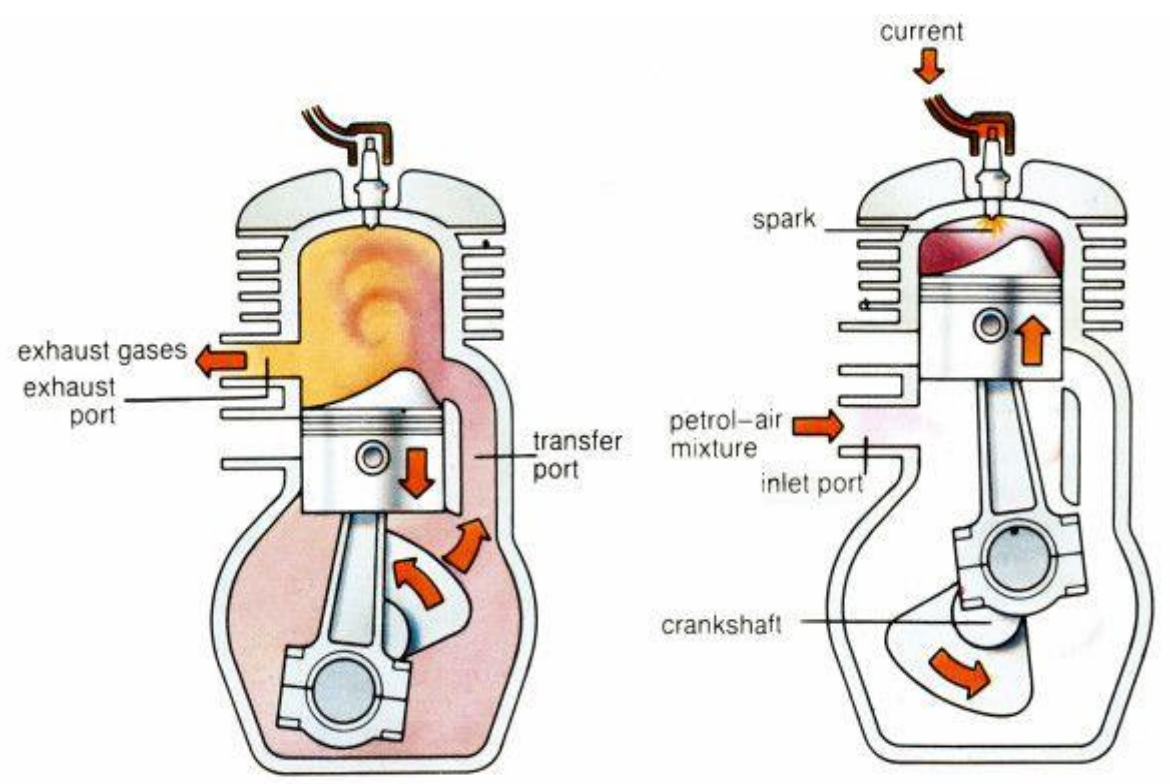

Figure 1. Shematic Diagram of a Two Stroke Engine (Cameron, 2015) 


\section{MATERIALS AND METHOD}

The key materials used in the analysis are, AutoCAD 2018 for the conceptual presentation, and Solidworks 2013 for modeling and simulation. An engine block model was used as a reference model. Calculations were done to calculate the various fins parameters for the development of the modified model. A solid model of the engine blocks were developed and simulated using the solidworks 2013 simulation software. A steady state and transient state thermal analysis were carried out on the two models to ascertain their thermal performance. Also a computational fluid dynamics analysis were also carried on the two models to investigate the aerodynamics behavior of the engine block models. The simulation results for the two models were compared to ascertain their thermal and aerodynamics behaviours.

\subsection{Conceptualization and Analysis}

The wet and dry cylinders liners of a four stroke engines are circular and cylindrical in shape. This makes the cylinder to have uniform thermal and structure stress distribution. Therefore the engine block of the two stroke engine should also be made circular in design in order to enhance its heat dissipation, aerodynamics and uniform stress distribution. For this reason, the modified model of the two stroke spark ignition engine block was made be circular in design. Figure 2 shows the conceptual development.

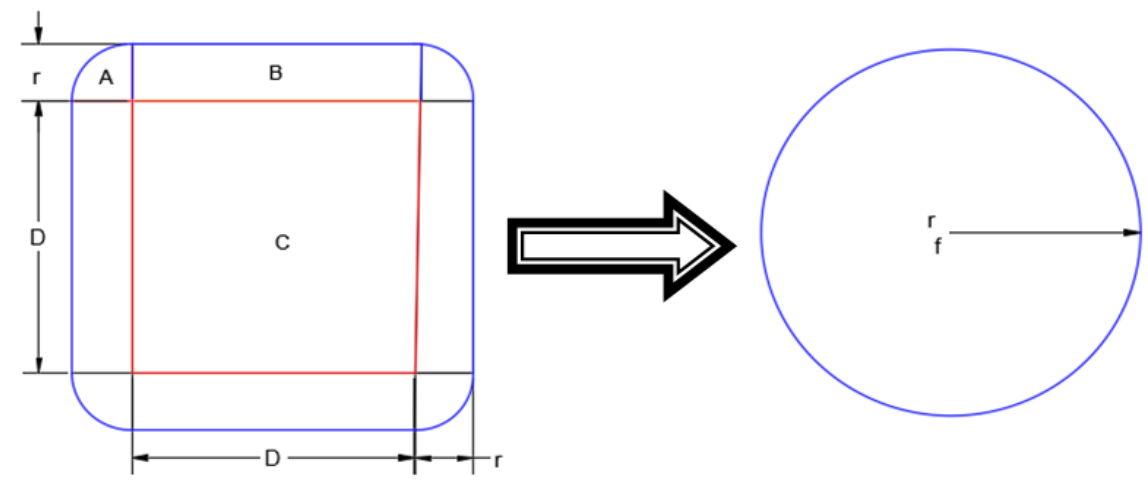

Figure 2. Conceptual Development

\subsubsection{Fins Outer Radius}

The cross sectional area of the reference model is equal to the cross sectional area of the modified model as illustrated in Figure 2.

$$
4 A+4 B+C=\pi r_{f}
$$

$r_{f} \quad:$ Fin Radius (outer radius of the engine block)

$$
\begin{array}{ll}
\text { A } & \text { : Sector } \\
\text { B } & \text { : Rectangle } \\
\text { C } & \text { : Square }
\end{array}
$$

$$
\frac{4 \emptyset \pi r^{2}}{360}+4 r b+b^{2}=\pi r_{f}^{2}
$$

$\varnothing=90^{\circ}$ (Angle of sector A in Figure 1)

$$
r_{f}=\sqrt{\frac{r(\pi r+4 b)+b^{2}}{\pi}}
$$




\subsubsection{Fins Length}

Unlike the reference model, the length of the fin of the modified is uniformly equal all round the engine cylinder. This would ensure uniform stress distribution round the engine cylinder The length of the fins is given by;

$$
L_{f}=r_{f}-r_{b}
$$

\subsubsection{Normalized Fins Radius}

The Normalize fins radii is given by Acosta-Iborra \& Campo (2013) as;

$$
R_{f}=\frac{r_{f}}{r_{b}}
$$

While the normalize radii ratio should be within the range of;

$$
1 \leq \frac{r_{f}}{r_{b}} \leq 5
$$

\subsubsection{Convective Heat Transfer}

Annand's Correlation is used for calculating the Convective heat transfer $\mathrm{h}_{\mathrm{g}}$ (Lounici et al., 2010),

$$
\begin{gathered}
h_{g}=a \cdot \frac{k_{g}}{B} \cdot R e^{0.7}+b \cdot \frac{\left(T_{g}^{4}-T_{w}^{4}\right)}{\left(T_{g}-T_{w}\right)} \\
a=0.35-0.8, \text { and } b=4.3 \times 10^{-9} \mathrm{~W} / \mathrm{m}^{2} \mathrm{~K}^{-4} \\
\operatorname{Re}=\frac{\rho \cdot V \cdot L}{\mu}
\end{gathered}
$$

\subsubsection{Heat Flux}

Gangwar et al. (2017) noted that Woschni, Equation 9 calculates heat flux as a function of the cylinder bore, the characteristic velocity, the cylinder pressure and temperature as,

$$
q=a \cdot D^{-0.2} \cdot p^{0.8} \cdot V^{0.8} \cdot T^{-0,53} \cdot\left(T_{g}-T_{w}\right)
$$

D : Cylinder Bore (m)

L : Characteristic Length (m)

P : Pressure (pa)

q : Heat Flux $\left(\mathrm{W} / \mathrm{m}^{2}\right)$

$\mathrm{T} \quad$ : Temperature (K)

V : Characteristic Velocity $(\mathrm{m} / \mathrm{s})$

$\mu \quad$ : Dynamic Viscosity (N.s/m²)

$\rho \quad:$ Density $(\mathrm{kg} / \mathrm{m})$ 


\subsection{Finite Element Formulation for the Thermal Analysis}

Figure 3 illustrate the temperature distribution on the cylinder wall. By using finite element method and assuming a linear variation of temperature. The resulting stiffness matrix is given by Lewis et al. (2004) as;

$$
\begin{aligned}
& {[K]=\frac{2 \pi k}{l} \frac{\left(r_{i}+r_{j}\right)}{2}\left[\begin{array}{cc}
1 & -1 \\
-1 & 1
\end{array}\right]+2 \pi r_{o} h\left[\begin{array}{ll}
0 & 0 \\
0 & 1
\end{array}\right]} \\
& Q^{e}=h T_{\infty} 2 \pi r_{o}\left[\begin{array}{l}
0 \\
1
\end{array}\right]
\end{aligned}
$$

It is also noted in Hutton (2004), that the Finite Element Equation with conduction and convection can be expressed as

$$
\begin{aligned}
& \left(\left[K_{T}^{e}\right]+\left[K_{C}^{e}\right]\right)[T]=\left[Q^{e}\right]+\left[q^{e}\right] \\
& \left(\frac{2 \pi k}{l} \frac{\left(r_{i}+r_{j}\right)}{2}\left[\begin{array}{cc}
1 & -1 \\
-1 & 1
\end{array}\right]+2 \pi r_{o} h\left\{\begin{array}{ll}
0 & 0 \\
0 & 1
\end{array}\right]\right)\left[\begin{array}{l}
T_{i} \\
T_{j}
\end{array}\right]=\left[\begin{array}{ll}
Q_{i}^{e} & q_{i}^{e} \\
Q_{j}^{e} & q_{j}^{e}
\end{array}\right]
\end{aligned}
$$

e : Element, $\quad \mathrm{i}, \mathrm{j}:$ Nodes, $\quad l$ : Length $(\mathrm{m})$

$Q^{e} \quad$ : Thermal load corresponding to the heat source $\left(\mathrm{W} / \mathrm{m}^{3}\right)$

$\mathrm{q} \quad$ : Vector of nodal heat flows across the cross-section $\left(\mathrm{W} / \mathrm{m}^{3}\right)$

$T_{\infty} \quad$ : The ambient temperature of the brake drum $(\mathrm{K})$

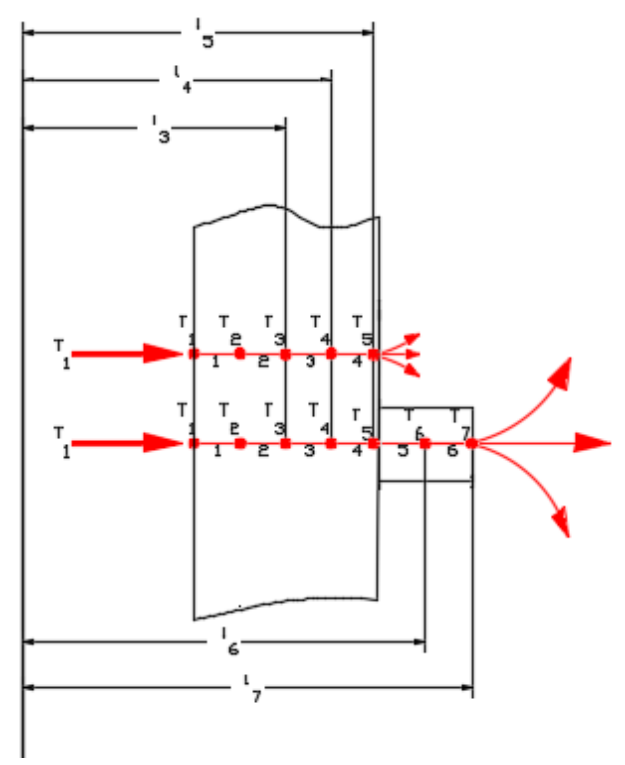

Figure 3. Sectional of the Engine Cylinder with Nodal Points

In situation where the Prandtl number differ from unity, the Nuseelt number can be express as (Broekaert et al., 2016),

$$
N u=0.332 \cdot \operatorname{Re}^{1 / 2 \cdot \operatorname{Pr}^{1 / 3}}
$$

The Reynold ( $R e$ ) was expressed in Equation 8, while the Prandtl Number $(P r)$ is expressed as;

$$
\operatorname{Pr}=\frac{\mu \cdot C_{p}}{k}
$$


In fluid mechanics, mach number $(\mathrm{M})$ is define as the ratio of the inertia force $\left(F_{i}\right)$ to the elastic force $\left(F_{e}\right)$. It is expressed as;

$$
\begin{aligned}
& M=\sqrt{\frac{\text { Inertia Force }}{\text { Elastic Force }}}=\sqrt{\frac{\rho A V^{2}}{K L^{2}}} \\
& M=\frac{V}{\sqrt{K / \rho}}
\end{aligned}
$$

While the square of the mach number is called Cauchy Number (C) (Al-Shemmeri, 2012).

The coefficient of drag $C_{D}$ is expressed as:

$$
\begin{aligned}
C_{D} & =\frac{\operatorname{Drag} \text { Force }\left(F_{D}\right)}{\text { Kinetic Pressure }\left(K_{P}\right) \cdot \text { Frontal Area }\left(A_{f}\right)} \\
C_{D} & =\frac{F_{D}}{\rho V^{2} / 2 \cdot A_{f}}=\frac{2 F_{D}}{\rho V^{2} \cdot A_{f}} \\
F_{D} & =\frac{C_{D} \cdot \rho V^{2} \cdot A_{f}}{2}
\end{aligned}
$$

When a given body is moving through a fluid, it does work on the fluid to overcome the drag force. This rate of work done is given by the power equation:

$$
P=F_{D} \cdot V_{b}
$$

Where, $\mathrm{P}$ is the power needed to overcome the drag force $\left(F_{D}\right)$ and $\left(V_{b}\right)$ is the speed of the body (Elger et al., 2016).

\subsection{Modelling and Simulation}

During the simulation process, the engine block models were treated under the same boundary conditions to ascertain the model with an improved heat dissipation and aerodynamics performance. Most engine blocks are made of cast iron material. They are designed to withstand high temperature of more than $2000^{\circ} \mathrm{C}(\mathrm{Babu}$ et al, 2013; Ansari et al., 2020). Therefore, a cast iron material was selected during the simulation analysis. Just as Ansari et al. (2020), a steady state and transient thermal analysis were performed on the two models at the temperature of $1000^{\circ} \mathrm{C}$ and ambient temperature $20^{\circ} \mathrm{C}$. While during the computational fluid dynamics analysis, the models were subjected to air stream at the velocity of $60 \mathrm{~m} / \mathrm{s}$.

\subsubsection{Model Assumption}

In order to unify the analysis, the two models were treated under the same boundary conditions. While in order to simplify the analysis, It was assumed that, after the expansion stroke of the engine, the heat dissipation needs to be carried out at a fast rate to prevent unusual heating of the combustion chamber and the entire engine. Therefore the heat dissipation of the engine was assumed to take place through the entire wall of the engine cylinder. It was also assumed that, the arrangements of the fins can affect the aerodynamic behavior of the engine block. Therefore the two models were subjected under the same air velocity. Figure 4 shows the solid and the meshed model of the reference and the modified model of the engine block respectively. 


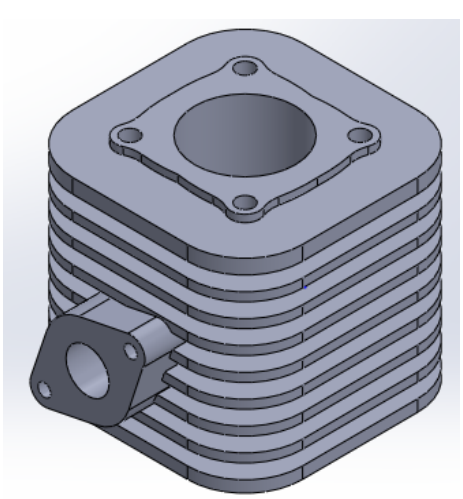

(a)

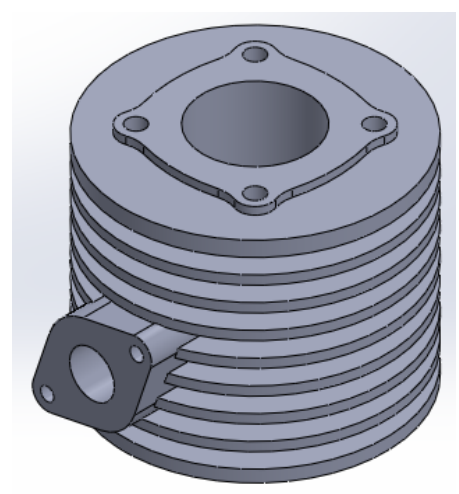

(c)

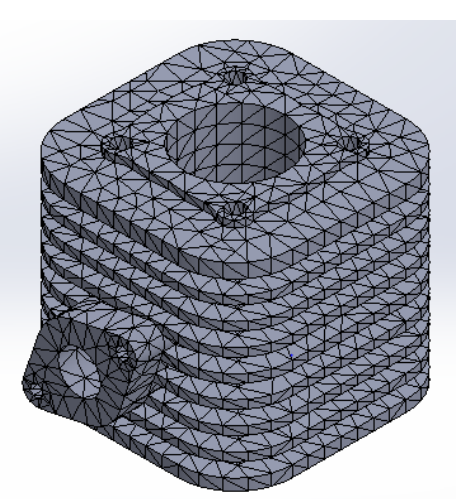

(b)

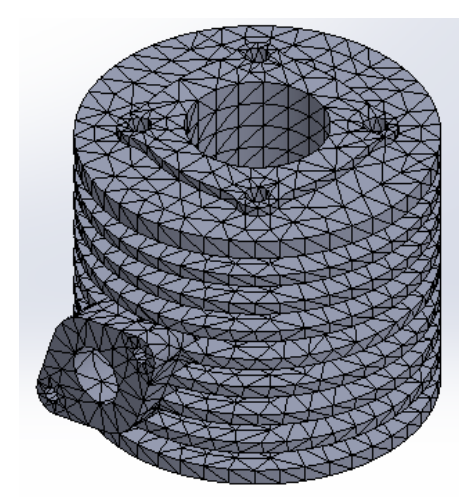

(d)

Figure 4. Engine Block Models, a) and b) Solid and Meshed Model of the Reference Model, c) and d) Solid and Meshed Model of the Modified Model

\section{RESULTS AND DISCUSSION}

The simulation result shows that, no element of the two models was damaged as the result of distortion; as this could affect the simulation results. The result also shows that, the two models have the same Jocobian point (4), \% distortion (0), element size $(0.0160 \mathrm{~m})$, and element tolerance $(00080)$. This justified that, the two models were treated under the same boundary condition. Meanwhile, the modified model shows high number of elements (13758) and nodal points (23949) than the reference model (13285 and 23290). This shows that, the surface area of the modified model has been extended in order to enhance its heat dissipation.

A steady state thermal analysis was carried out on both models under the same boundary conditions. The analysis was to investigate and compare the thermal performance of the models under the same boundary conditions. The rate of heat transfers between the combustion chamber and the surrounding are not uniform and unsteady, and difficult to evaluate. The steady state analysis showed that, the maximum and minimum temperature distribution of the refrence model (Figure 5a), are greater than that of the modified model (Figure 6a). The low temperature distribution shown by the modified model implied that the model has high rate of heat dissipation than the reference model.

Temperature gradient is the change in temperature over a given length of material or component. The two models where investigated under the same temperature condition. However, the refrence model (Figure 5b) shows a higher value of temperature gradient than the modified model (Figure 6b). This showed that, the temperature changes through a longer distance from the inner wall of the engine cylinder to the tip of the fins of the modified model than that of the reference model. This increase in distance is as the result of the geometric modification of the fins on the surface of the modified engine block.

The modified model has high value of heat flux than the reference model. The heat flux or thermal flux, sometimes referred to as heat flux density or heat flux density, is the flow of energy per unit of area per unit 
of time. The simulation results showed that, the rate of heat transfer of the reference model (Figure $5 \mathrm{c}$ ) is less than that of the modified model (Figure 6c). This implied that more heat was dissipated from the fins of the modified model compare to the reference model.

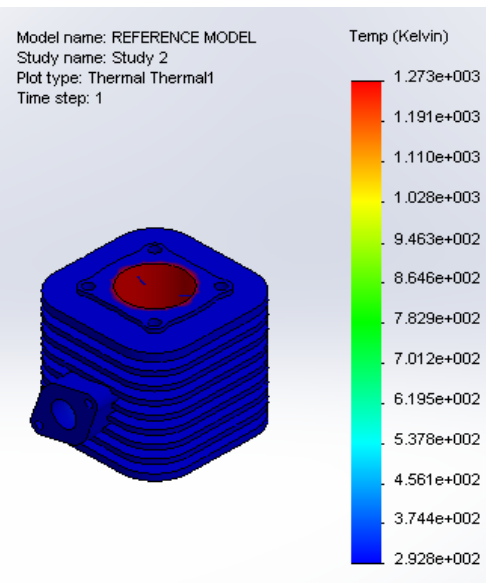

(a)

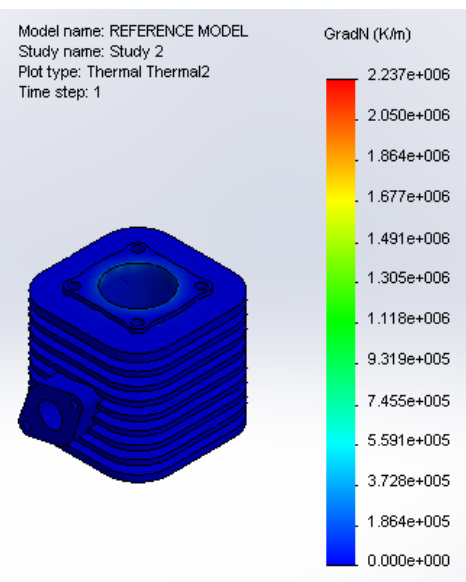

(b)

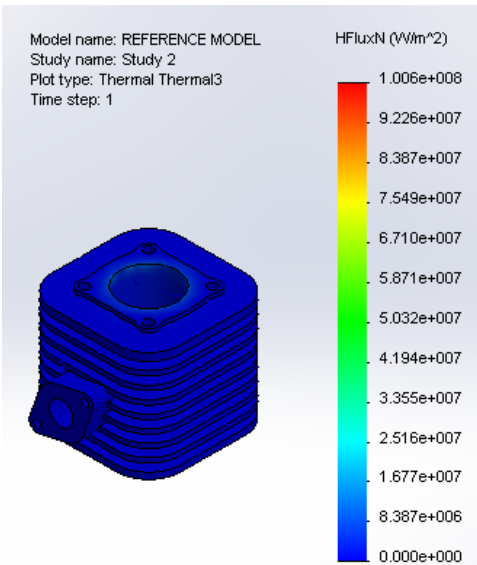

(c)

Figure 5. Steady State Thermal Analysis for Reference Model, a) Temperature Distribution, b) Thermal Gradient, c) Heat Flux

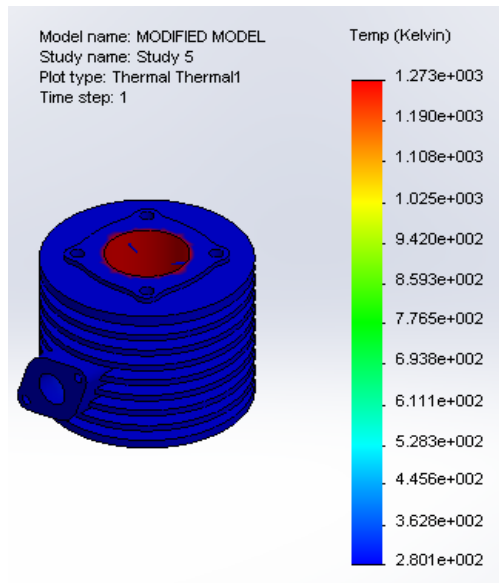

(a)

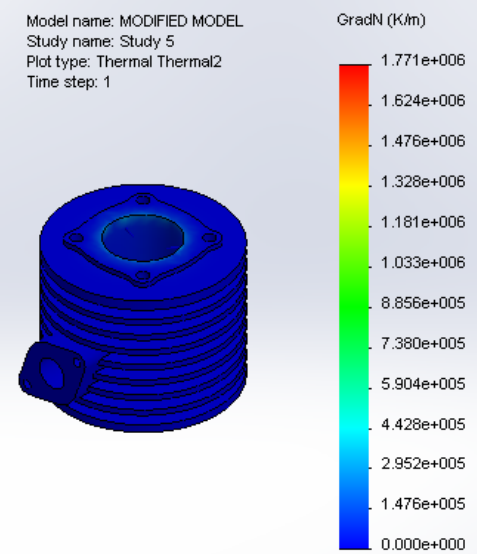

(b)

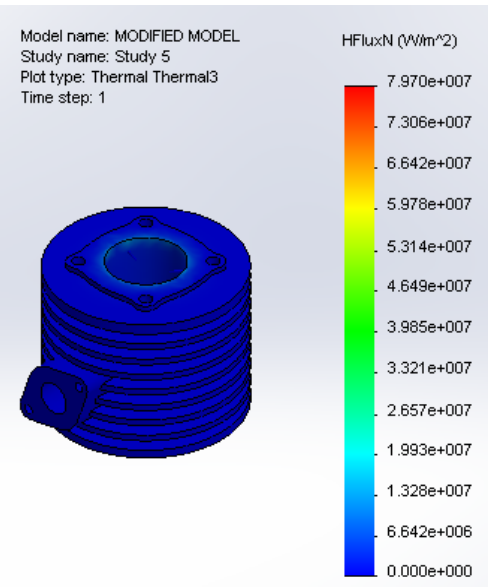

(c)

Figure 6. Steady State Thermal Analysis for Modified Model a) Temperature Distribution, b) Thermal Gradient, c) Heat Flux

The transient thermal analysis evaluates temperature and heat flux of the model over a assigned period of time. The transient thermal analysis for this analysis was carried out over a period of 300 seconds, and time increments of 10 seconds. Therefore the simulation calculated the results 30 times. The results showed that, the reference model (Figure 7a) has higher temperature over this given period of time, than that of the modified model (Figure 8a). This also implied that more amount of heat energy has been dissipated from the modified model, than that of the reference model. Meanwhile the temperature gradient and the heat flux of the reference model (Figure 7b and 7c) are less than that of the modified model (Figure 8b and 8c), which implied that more heat were dissipated at a fast rate and within a shorter period of time compare to that of the reference model. The analysis showed that, the fins has improved the thermal performance of the modified engine block. The high temperature shown by the reference model implies that, the model retained more amount of heat energy. This retained amount of heat energy in a given component is the major cause of thermal problems associated with some mechanical systems (Bako et al., 2020). Therefore, this retained heat energy in the engine block is the major causes of the thermal problems associated with the two stroke spark ignition engine as earlier mentioned in the paper. 


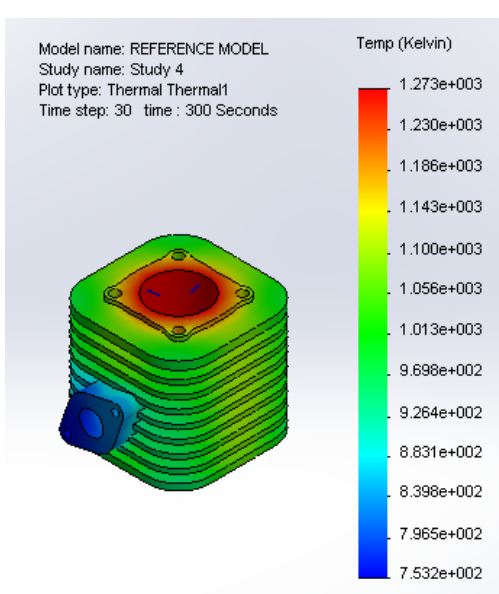

(a)

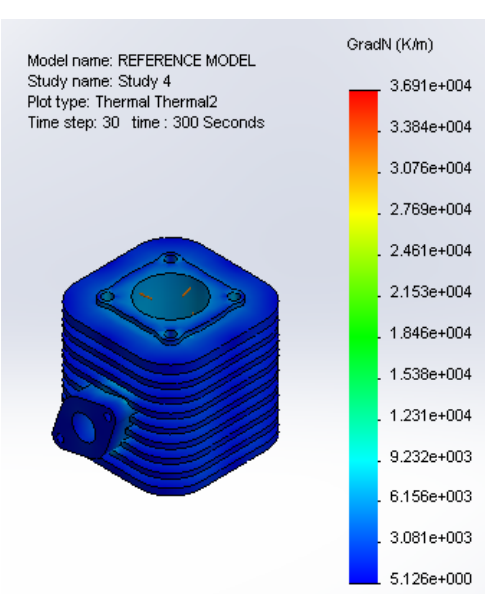

(b)

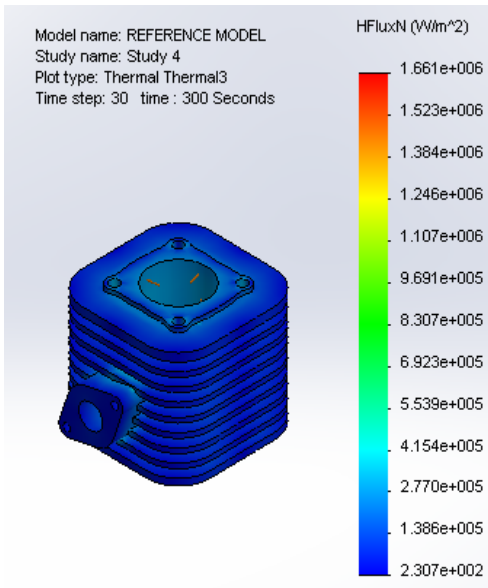

(b)

Figure 7. Transient Thermal Analysis for Reference Model, a) Temperature Distribution, b) Thermal Gradient, c) Heat Flux

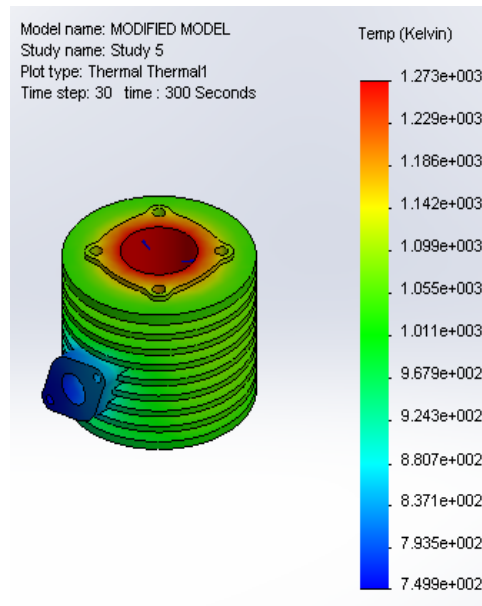

(a)

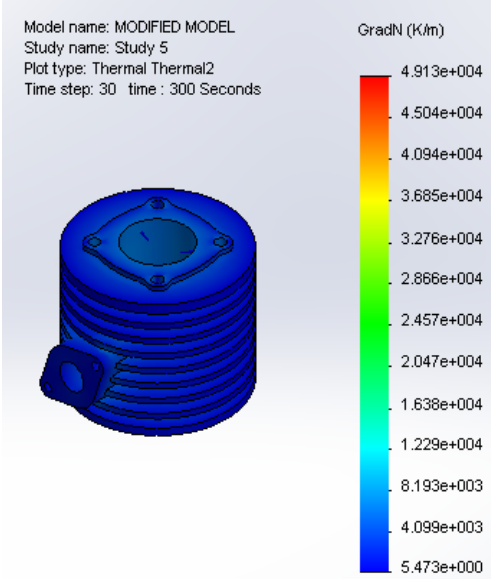

(b)

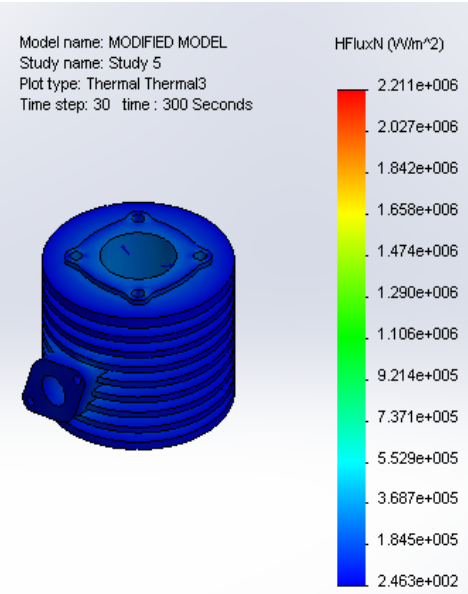

(c)

Figure 8. Transient Thermal Analysis for Modified Model,

a) Temperature Distribution, b) Thermal Gradient, c) Heat Flux

The computation fluid dynamics analysis of the engine block models analyzed the impact of air flow on the models. During the computational fluid dynamics analysis, it takes 221 iterations at 42 minutes 53 seconds on the modified model, and 226 iterations at 8 hours, 05 minutes, 24 seconds for reference model respectively, both to complete the simulations. The higher iteration taken by the reference model is as the result of the geometry complicity of the model fins arrangemnet of the model. The complicity of the fins arrangement of the reference model would affect its air resistance, air flow round the engine block, and its heat dissipation (Table 1).

The results (Table 1) shows that, the reference model has high total pressure and dynamic pressure than the modified model. This increase in pressure, increases the drag force acting on the engine. This shows the modified model has high air flow velocity than the reference model. This is due to the fins modification round the engine block. This makes the engine block model to have low air restriction on the surface of the engine block. In line with Equation 17 and 19 above, the high velocity shown by the modified model would reduce the drag coefficient and reduce the power required to overcome the drag force.

The CFD results (Table 1) shows that the reference model has high temperature than the modified model. This agreed with the results obtained earlier during the thermal analysis of the engine blocks. Meanwhile, 
heat is transferred from a region of higher temperature to a region of lower temperature. During the simulation, the surrounding air of the modified model has low fluid thermal conductivity, specific heat, and fluid density. This is as the result of the heat transfer enhancement by the fins in the modified model. While the high fluid thermal conductivity, specific heat, and fluid density shown by the reference model, implies that the some amount heat are retained in the engine block. This retained heat energy contributes to thermal problems earlier mentioned.

Table 1. Computational Fluid Dynamics Analysis Results

\begin{tabular}{|c|c|c|c|c|c|c|}
\hline \multirow{2}{*}{ Parameter } & \multicolumn{3}{|c|}{ Reference Model } & \multicolumn{3}{|c|}{ Modified Model } \\
\hline & Minimum & Maximum & Average & Minimum & Maximum & Average \\
\hline Pressure $(\mathrm{Pa})$ & 15.755641 & $1.01604 \mathrm{E}+14$ & $6.4888 \mathrm{E}+11$ & 149.497139 & $1.03599 \mathrm{E}+14$ & $3.04532 \mathrm{E}+11$ \\
\hline Total Pressure $(\mathrm{Pa})$ & 161.965128 & $5.77247 \mathrm{E}+43$ & $1.79168 \mathrm{E}+37$ & 281.215975 & $5.42705 \mathrm{E}+36$ & $3.69148 \mathrm{E}+32$ \\
\hline Dynamic Pressure $(\mathrm{Pa})$ & 17.216195 & $3.37613 \mathrm{E}+13$ & 15634822500 & 61.1102775 & $3.56193 \mathrm{E}+13$ & 5521918770 \\
\hline Density (Fluid) $\left(\mathrm{kg} / \mathrm{m}^{3}\right)$ & 0.497496662 & 1158911190 & 3392130.97 & 0.033950154 & 1142510500 & 1269771.46 \\
\hline Velocity (m/s) & 1.00878893 & 8350.57759 & 77.0553136 & 3.76379057 & 774.338598 & 84.8789113 \\
\hline Velocity (X) (m/s) & -1867.81072 & 8350.33827 & -1.47732447 & -772.930548 & 765.738329 & 2.7958421 \\
\hline Velocity $(\mathrm{Y})(\mathrm{m} / \mathrm{s})$ & -2517.73893 & 1743.85097 & 33.179026 & -773.183945 & 773.20881 & 25.963943 \\
\hline Velocity (Z) (m/s) & -947.911654 & 1023.53305 & 1.56786409 & -768.297218 & 701.44137 & -6.16695285 \\
\hline Mach Number [ ] & 0.002930754 & 1414601.35 & 2.1356413 & 0.010934759 & 128163.333 & 10.7358892 \\
\hline Turbulent Viscosity (Pa s) & $1.63819 \mathrm{E}-07$ & 30784.4769 & 175.563996 & 4.62505E-07 & 1879665.02 & 163.09085 \\
\hline Turbulent Time [s] & $1.35451 \mathrm{E}-07$ & 0.157767018 & 0.151551284 & $7.83279 \mathrm{E}-06$ & 0.157767018 & 0.143583217 \\
\hline Turbulence Length (m) & $6.57869 \mathrm{E}-09$ & 0.001905 & 0.001836869 & 4.97949E-07 & 0.001905 & 0.001755192 \\
\hline Turbulence Intensity (\%) & 0.001141236 & 446.495556 & 0.545262818 & 0.007851275 & 73.049692 & 0.65393956 \\
\hline Turbulent Energy $(\mathrm{J} / \mathrm{kg})$ & 0.004163308 & 98371.0652 & 87.2651398 & 0.005394532 & 52080.3403 & 73.8013881 \\
\hline Turbulent Dissipation (W/kg) & 0.034227686 & 30915523800 & 6551457.21 & 0.034227686 & 3396071120 & 2513835.55 \\
\hline Specific Heat $(\mathrm{Cp})(\mathrm{J} /(\mathrm{kg} \mathrm{K}))$ & 1006.0876 & 2860.8392 & 1007.16168 & 1006.0876 & 1029.115 & 1006.96882 \\
\hline Dynamic Viscosity (Pa s) & 0.00000604 & 0.0000955 & $1.81376 \mathrm{E}-05$ & 0.00000604 & $1.8239 \mathrm{E}-05$ & $1.77864 \mathrm{E}-05$ \\
\hline Prandtl Number ( ) & 0.53679653 & 0.797692716 & 0.707883917 & 0.707362959 & 0.797692716 & 0.709424297 \\
\hline Temperature /Fluid (K) & $6.8792 \mathrm{E}-10$ & 3051.16637 & 293.768406 & $9.14212 \mathrm{E}-08$ & 294.981023 & 286.170573 \\
\hline Total Temperature $(\mathrm{K})$ & 238.8894 & 33879.6667 & 303.242027 & 213.475494 & 295.035451 & 294.75345 \\
\hline Stagnation Density $\left(\mathrm{kg} / \mathrm{m}^{3}\right)$ & 3.19316023 & $2.06696 \mathrm{E}+36$ & $4.63867 \mathrm{E}+29$ & 0.034471458 & $3.87034 \mathrm{E}+28$ & $2.61904 \mathrm{E}+24$ \\
\hline Total Enthalpy (J/kg) & 245844.725 & 34866073 & 308678.489 & 243360.145 & 304628.393 & 299752.863 \\
\hline Fluid Thermal Conductivity W/(m K) & 0.007792292 & 0.486 & 0.026339827 & 0.007792292 & 0.025963111 & 0.024459105 \\
\hline
\end{tabular}

\section{CONCLUSION}

This study presents thermal and aerodynamics analysis of a two stroke spark ignition engine block. The modified model shows uniform fins arrangement round the engine cylinder in order to enhance its strength and its heat dissipation. The low temperature shown by the modified model with high temperature gradient and heat flux, indicates that, the modified model has high heat dissipation rate than the reference model, which will subsequently improve the engine efficiency.

The CFD analysis shows that, the reference model has high total pressure and dynamic pressure than the modified model. This increase in pressure, increases the drag force acting on the model. While the modified model has high air flow velocity than the reference model; due to its fins modification. This made the 
modified model to have low air restriction. The CFD results also shows that the reference model has higher temperature than the modified model. This agreed with the results obtained earlier during the thermal analysis of the engine blocks. This analyis also shows that the modified engine block model would have the following advantages over the reference model;

1. High heat dissipatio rate which would minimise the thermal problem associated with the two stroke spark ignition engines.

2. Low aerodynamic resistance, which would also lead to low fuel consumption and easy circulation of air round the engine block.

3. Improved engine block strength, which would also reduce engine vibration.

4. Low wearing of engine components as a result of friction; this would be as the result of the high heat dissipation rate and improved engine block strength.

5. The engine oil of the modified engine block would have long service life due to its low temperature which would prolong the engine oil lubricating power.

This paper has provided a method of developing a modified model of a two stroke spark ignition engine. It is hereby recommended that, physical validation should be carried out to ascertain the effectiveness of the modified model. The strength and heat dissipation rate of the engine block can also be improve by, converting the fins of the modified model into a triangular fins of equal length, and fins base; and also by adding the remaining part of the fin to the engine cylinder.

\section{CONFLICT OF INTEREST}

The authors of this manuscript have hereby declared that, there is no conflict of interest associated with the publication of this paper.

\section{REFERENCES}

Acosta-Iborra, A., \& Campo, A. (2013). Approximate Analytic Analysis of Annular Fins with Uniform Thickness by way of the Mean Value Theorem for Integration that Avoids Modified Bessel Functions. Latin American and Caribbean Journal of Engineering Education, 7(1), 1-23.

Al-Shemmeri, T. (2012). Engineering Fluid Mechanics. Bookboon Learning.

Ansari, M. B., Haque, M. F. U., \& Joshi, P. S. (2020). Design and Analysis of Engine Block. International Research Journal of Engineering and Technology, 7(5), 3514-3520.

Babu, G., \& Lavakumar, M. (2013). Heat Transfer Analysis and Optimization of Engine Cylinder Fins of Varying Geometry and Material. IOSR Journal of Mechanical and Civil Engineering, 7(4), 24-29.

Babu, G. S., Jagadeesh, S. D. V. S., Saicharan, U. B., \& Praneeth, P. R. S. (2013). Analysis of a Single Cylinder Combustion Engine using CFD. International Journal of Innovative Technology \& Exploring Engineering, 2(5), 164-167.

Bakare, A. O., Nasir, A., Abiodun, O. R., \& Bako, S. (2016). Combined Cycle Gas Turbine: Operation and Performance Analysis. In: Proceedings of the 1st AGM and Conference of the Nigerian Institution of Mechanical Engineers (pp. 57-68), Minna, Nigeria.

Bako, S., Nasir, A., Ige, B., \& Musa, N. (2020). Cavitational deterioration of diesel power plant cylinder liner. Journal of Mechanical and Energy Engineering, 4(3), 239-246. doi:10.30464/jmee.2020.4.3.239

Bako, S., Dogo, J. N., Umar, M. B., \& Jesuloluwa, S. I. (2021). Development and Structural Analysis of a Modified Two Stroke Spark Ignition Engine Block. In: Proceedings of the 5th AGM and Annual National Conference of the Nigerian Institution of Mechanical Engineers (pp 57-68), Minna, Nigeria.

Bernard, C., \& Baranescu, R. (1999). Diesel Engine Reference Book. England: Butterworth-Heinemann.

Blarigan, P. V., \& Keller, J. O. (1998). A hydrogen fuelled internal combustion engine designed for single speed/power operation. International Journal of Hydrogen Energy, 23(7), 603-609. doi:10.1016/S03603199(97)00100-6 
Borman, G., \& Nishiwaki, K. (1987). Internal-combustion engine heat transfer. Progress in Energy and Combustion Science, 13(1), 1-46. doi:10.1016/0360-1285(87)90005-0

Broekaert, S., Demuynck, J., De Cuyper, T., De Paepe, M., \& Verhelst, S. (2016). Heat transfer in premixed spark ignition engines part I: Identification of the factors influencing heat transfer. Energy, 116(1), 80-391. doi:10.1016/j.energy.2016.08.065

Cameron, K. (2015). Two Stroke Engines: Defining Their Purpose. (Accessed:03/12/2021) www.cycleworld.com/2015/04/06/two-stroke-motorcycle-engines-explained-tech-talk-by-kevin-cameron/

Dempsey, P. (2010). Two-Stroke Engine Repair \& Maintenance. New York: McGraw-Hill Companies.

Elger, D. F., LeBret, B. A., Crowe, C. T., \& Robertson, J. A. (2016). Engineering Fluid Mechanics (11th ed.). Hoboken: John Wiley \& Sons, Inc.

Gangwar, A., Singh, A., \& Pratap, A. (2017). Performance and Analysis of Two Stroke Dual and Triple Spark plug Single Cylinder SI Engine with Gasoline fuel. International Journal of Thermal Technologies, 7(4), 204-206.

Hutton, D. V. (2004). Fundamental of Finite Element Analysis. New York: Mcgraw-Hill Companies.

Jain, A., Saraswat, A. A., \& Shukla, O. P. (2016). A Survey on Heat Transfer of Air Cooled Internal Combustion Engine Various Fin Cutting Shape. International Research Journal of Engineering and Technology, 3(2), 1413-1418.

Jiang, S. (2015). Numerical Analysis of Two-Stroke Engine with Direct Injection and Jet Ignition. BSc Thesis, School of Aerospace Mechanical and Manufacturing Engineering, College of Science Engineering and Health, RMIT University, Melbourne.

Khan, T. A., \& Shaikh, R. (2016). Performance and Emission Analysis of Two Stroke Dual Sparkplug SI Engine. IOSR Jourmal of Mechanical \& Civil Engineering, (Special Issue: 5th National Conference on RDME) 2, 50-53. doi:10.9790/1684-1500850-53

Lewis, R. W., Nithiarasu, P., \& Seetharamu, K. N. (2004). Fundamentals of Finite Element Method for Heat and Fluid Flow. Hoboken: John Wiley and Sons Ltd. doi:10.1002/0470014164

Lounici, M. S., Loubar, K., Balistrou, M., \& Tazerout, M. (2010). Investigation on heat transfer evaluation for a more efficient two-zone combustion model in the case of natural gas SI engines. Applied Thermal Engineering, 31(2-3), 319-328. doi:10.1016/j.applthermaleng.2010.09.012

Rao, M. N. P. R., \& Vardhan, T. V. (2013). Thermal Analysis of Engine Cylinder Fins By Varying Its Geometry and Material. International Journal of Engineering Research \& Technology, 2(8), 404-412.

Schneider, S., Chiodi, M., Friedrich, H., \& Bargende, M. (2016). Development and Experimental Investigation of a Two-Stroke Opposed-Piston Free-Piston Engine. SAE Technical Paper 2016-32-0046. doi: $\underline{10.4271 / 2016-32-0046}$

Subramanian, T. S., Murali, B. S., Vairamuthu, M., Saravanan, M. V., \& Kumar, M. M. (2019). Design and Analysis of Cylinder and Cylinder Head of 6-Stroke SI Engine for Weight Reduction. International Journal of Innovative Research in Science, Engineering \& Technology, 8(3), 3276-3288.

Thomas, G. (2009). Computational Fluid Dynamics Modelling and Analysis of an Opposed Piston Internal Combustion Engine. MSc Thesis, School of Mechanical, Materials and Mechatronics Engineering, University of Wollongong, Wollongong.

Yeh, R-H., Liaw, S-P., \& Chang, M. (1997). Optimum Spacings of Longitudinal Convective Fin Arrays. Journal of Marine Science and Technology, 5(1), 6. doi:10.51400/2709-6998.2537 